\title{
Enhanced Sensitivity of Humidity Sensor Prepared using Vertically Aligned V-doped $\mathrm{TiO}_{2}$ Nanorods Array
}

\author{
M. Z. Musa, M. H. Mamat, M. A. Othman, I. B. Shameem, N. Vasimalai, M. F Malek, and M. Rusop
}

\begin{abstract}
This article reports on the performance of vanadium-doped $\mathrm{TiO}_{2}$ nanorod arrays (TNA)-based humidity sensor. The sensing material was prepared using a facile solution immersion method. Humidity sensor was fabricated using the prepared thin films and was tested using humidity chamber and a current measuring circuit, built with microcontroller. Improvement to the sensitivity was observed for the V-doped TNA sensor with sensitivity value of 15.0 compared to 9.9 for the undoped TNA sensor. The increased performance is attributed to the enlargement of nanorods diameter, improvement of crystallinity and the increase in oxygen vacancy defect sites of the $V$-doped sample.
\end{abstract}

Index Terms - humidity sensor, nanorods, titanium dioxide, vanadium

\section{INTRODUCTION}

$\mathrm{T}$ he amount of water molecules in the air is often referred to as the humidity. It is an important physical parameter as it can give significant effect to the human's everyday life. Accurate measurement of this quantity is needed in agricultural [1], food manufacturing [2], health monitoring $[3,4]$ and weather forecasting. To achieved this, various kinds of humidity sensors have been produced using materials such as polymers [4] and metal oxides.

Metal oxides have the advantage over polymers due to the robust nature of the material, enabling it to be employed in harsh condition such as in high temperature and chemically challenging environment. One of the proven effective metal oxides material is titanium dioxide $\left(\mathrm{TiO}_{2}\right)$. Armed with its high hydrophilicity and highly tunable

This manuscript is submitted on $7^{\text {th }}$ August 2020 and accepted on $11^{\text {th }}$ November 2020.This work was supported in part by the Ministry of Education, Malaysia (FRGS/1/2018/TK04/UITM/02/23) and Indian government (ASEAN-India Research Training Fellowship).

M.Z. Musa and M.H. Mamat are with the NANO-Electronics Centre (NET), Faculty of Electrical Engineering, Universiti Teknologi MARA (UiTM), $40450 \quad$ Malaysia (e-mail: mhmamat@uitm.edu.my, musa_zahidi59@uitm.edu.my).

N.Vasimalai and I.B. Shameem Banu are from B.S. Abdur Rahman Crescent Institute of Science and Technology, Chennai, India (e-mail: vasimalai2020@gmail.com, shameembanu@crescent.education).

M.F. Malek and M. Rusop are from NANO-SciTech Centre (NST), Institute of Science (IOS), Universiti Teknologi MARA (UiTM), 40450 Malaysia (email: mfmalek07@uitm.edu.my, rusop@uitm.edu.my)

$1985-5389 / \odot 2021$ The Authors. Published by UiTM Press. This is an open 68 access article under the CC BY-NC-ND license (http://creativecommons.org/ licenses/by-nc-nd/4.0/). nanostructure, $\mathrm{TiO}_{2}$ has become one of the preferred metal oxides for humidity sensor application. While $\mathrm{TiO}_{2}$ could exist in three crystalline phases of rutile (tetragonal), anatase (tetragonal) and brookite (orthorhombic) [5], most of the reported humidity sensor utilizes rutile or anatase phase $\mathrm{TiO}_{2}$.

A good humidity sensor should have high sensitivity, fast response/recovery time, and high stability [6]. Various efforts have been carried out by researchers to further improve the performance of $\mathrm{TiO}_{2}$-based humidity sensor. Fabrication of unique nanostructures such as nanosheets [7], nanoflowers [8], nanotubes [9], nanofibers [10], nanowires [11], and nanorods [12] have proven beneficial in enhancing the humidity sensor performance. Since the detection of humidity water molecules correlates with the adsorption of water molecules on the sensor surface [13], increment in the surface area are often cited to be the reason for the improvement.

In the case of one-dimensional (1D) nanostructures such as nanorods and nanowires, the direct pathway for charge carrier transport is said to be responsible for the enhancement in sensor performance. Having oriented structures ease the transport of electron if compared to other non-oriented nanostructures [5]. Meanwhile, there are also attempts by other groups to dope $\mathrm{TiO}_{2}$ with other elements such as cobalt [14], copper [15], and tin [16] to increase the sensitivity of humidity sensor. The purpose was to increase the carrier concentration by donation of extra charge carrier through substitutional doping [17]. Besides that, doping could also increase the oxygen vacancies sites. This type of defect helps the humidity detection by increasing water molecules adsorption sites [18]. A density-functional theory (DFT) calculation by Farzaneh et al. [10] showed that adsorption energy of water molecules to rutile $\mathrm{TiO}_{2}$ increased to $87 \%$ with the addition of ruthenium dopant.

In this work, we aim to combine these two approaches by synthesizing $\mathrm{V}$-doped $\mathrm{TiO}_{2}$ nanorod arrays (TNA) using a facile solution immersion method and to fabricate humidity sensor using the prepared thin films. V was chosen as the dopant as it has similar ionic radius as $\mathrm{Ti}$ ion [19] which would allow for smooth incorporation of the dopant. It has also been proven to improve the photocatalytic performance of $\mathrm{TiO}_{2}$. However, to the best of our knowledge, there have 
not been any report yet on the fabrication of V-doped TNAbased humidity sensor.

\section{MEthodOLOGY}

\section{A. TNA Preparation}

The TNA was prepared using method developed by Yusoff et al. [20]. Briefly, a solution was prepared by mixing deionized (DI) water with hydrochloric acid $(37 \%$, Merck) at 1:1 ratio in Schott bottles. $0.07 \mathrm{M}$ of tetrabutyl titanate $(97 \%$, Sigma-Aldrich) was added to the solution as the precursor. For V-doped sample, vanadium chloride was further added to the solution as the dopant source. The solution was stirred rigorously for 50 minutes before flourine-doped tin oxide (FTO)-coated glass substrate was positioned inside the bottle with the FTO layer facing upward. To allow for the growth of the nanorods, the bottle was placed inside an oven set at $150^{\circ} \mathrm{C}$. After 3 hours, the substrate was carefully taken out and rinsed with DI water before being blow-dried with nitrogen gas.

\section{B. Characterization}

The thin films' morphology was observed using fieldemission scanning electron microscopy (FESEM, JEOL JSM-7600F) and its structural properties was characterized using X-ray diffractometer (XRD, PANalytical X'pert PRO). For humidity sensor measurement, silver (Ag) metal contact was deposited on top of the thin films using thermal evaporator (ULVAC). The humidity sensor measurement was done inside a humidity chamber (ESPEC-SH261). Measurement system was built using Arduino ATmega2560 microcontroller, $100 \Omega$ resistor and a homemade acrylic stand as shown in Fig 1.

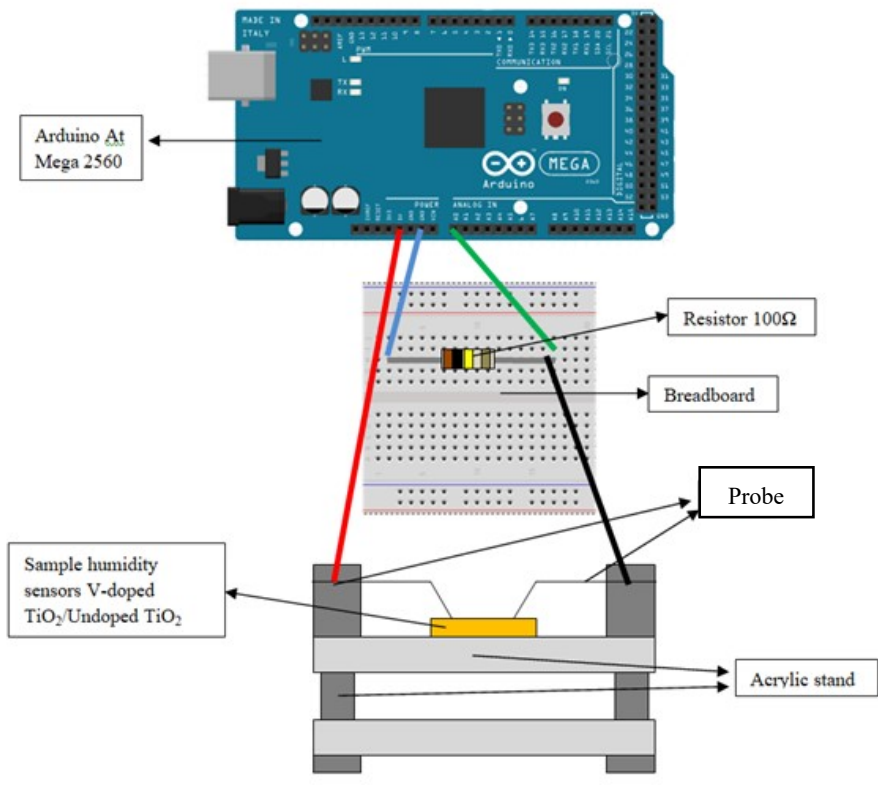

Fig. 1. Circuit connection of humidity measurement system.

\section{RESULT AND DISCUSSION}

\section{A. Structural Properties}

Fig. 2 shows the FESEM top view images of the prepared thin films. Both samples showed uniformed and vertically aligned nanorod arrays. The average nanorod diameter was measured at around $100 \mathrm{~nm}$ and $200 \mathrm{~nm}$ for the undoped and $\mathrm{V}$-doped $\mathrm{TiO}_{2}$ respectively, suggesting that the introduction of $\mathrm{V}$ increases the grain size of TNA. This result is in agreement with the report by Faia et al. [20]. It appears that the addition of $\mathrm{V}$ promotes the crystal growth of $\mathrm{TiO}_{2}$. As a result, the nanorods in the V-doped TNA sample are more closely packed compared to the undoped TNA.
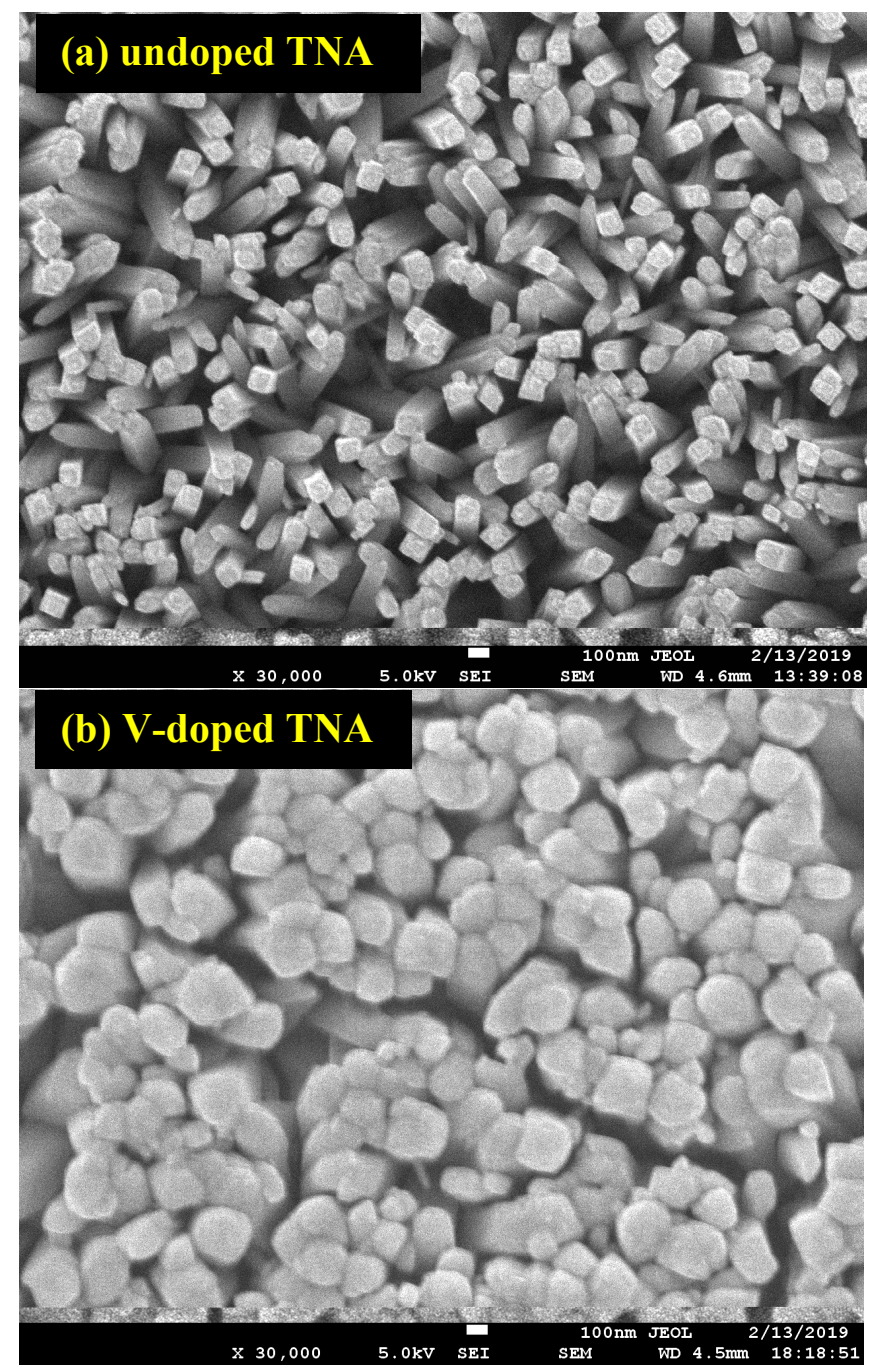

Fig. 2. FESEM top-view images of: (a) undoped TNA, (b) V-doped TNA at $30 \mathrm{k}$ times magnification.

The FESEM cross sectional view of the samples is shown in Fig. 3. From the figure, the average TNA thickness is estimated at $3.05 \mu \mathrm{m}$ and $2.17 \mu \mathrm{m}$ for the undoped and V-doped sample respectively. From this result, it can be concluded that the addition of $\mathrm{V}$ appears to 
increase the growth of the nanorod structural laterally while inhibiting its vertical growth. The FTO layer also clearly visible at the bottom of TNA. This FTO layer is essential as the seed layer for the vertical growth of TNA. Since it shares the same tetragonal structures as $\mathrm{TiO}_{2}$, it could provide a suitable nucleation sites for the growth of $\mathrm{TiO}_{2}$ crystals.

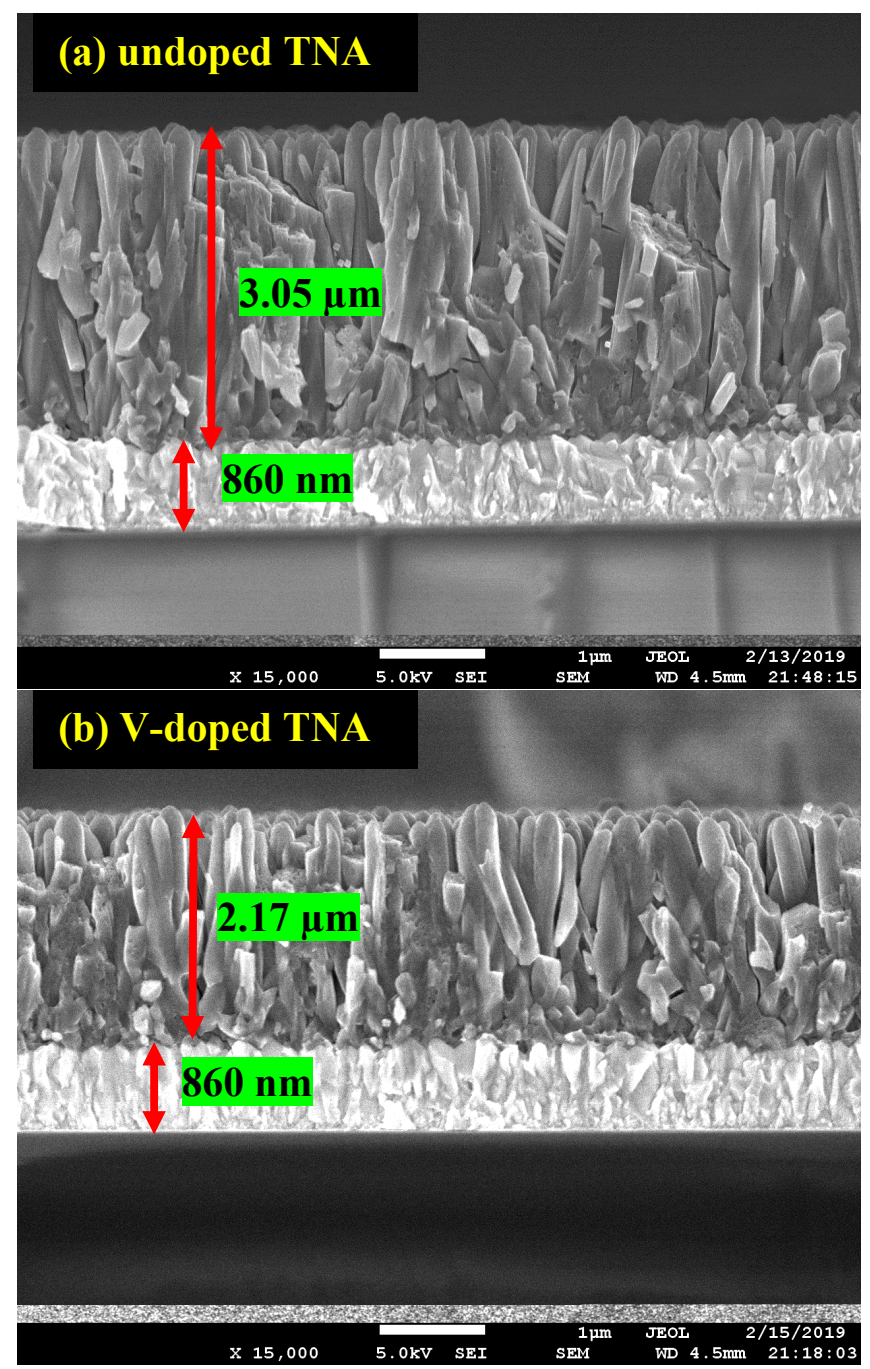

Fig. 3. FESEM cross-sectional view images of: (a) undoped TNA, and (b) V-doped TNA at $15 \mathrm{k}$ times magnification.

XRD spectra of the samples is shown in Fig. 4. Peaks which correspond to (110), (101), and (002) planes were observed for both of the samples indicating the presence of rutile phase $\mathrm{TiO}_{2}$. The absence of vanadium oxide's characteristic peaks suggests that either the $\mathrm{V}$ ions are incorporated in $\mathrm{TiO}_{2}$ lattice or vanadium oxide is too small to be detected by the XRD [22]. The V-doped TNA showed higher peak intensity for all $\mathrm{TiO}_{2}$ related peaks which suggests better crystallinity than the undoped TNA. This finding is supported by Liu et al. [22] which suggested that the doping of $\mathrm{V}$ in $\mathrm{TiO}_{2}$ lattice improved the growth of $\mathrm{TiO}_{2}$ nanoparticles and is in line with the previous FESEM result. The crystallite size of the samples was calculated using
Scherrer's equation as follows:

$$
D=\frac{K \lambda}{\beta \cos \theta}
$$

where $K$ represents a constant, given as $0.9, \lambda$ is the X-ray's wavelength (1.5418 $\AA), \theta$ denotes the diffraction angle while $\beta$ refers to full-width at half maximum (FWHM) of the peak. From the calculation of the peak which corresponds to (110) plane, the undoped TNA recorded crystallite size of $40.4 \mathrm{~nm}$ while the V-doped TNA crystallite size is $196.4 \mathrm{~nm}$. This significant enlargement of the $\mathrm{TiO}_{2}$ crystallite size with the addition of $\mathrm{V}$, further confirms the crystal growth promotion caused by $\mathrm{V}$ doping.

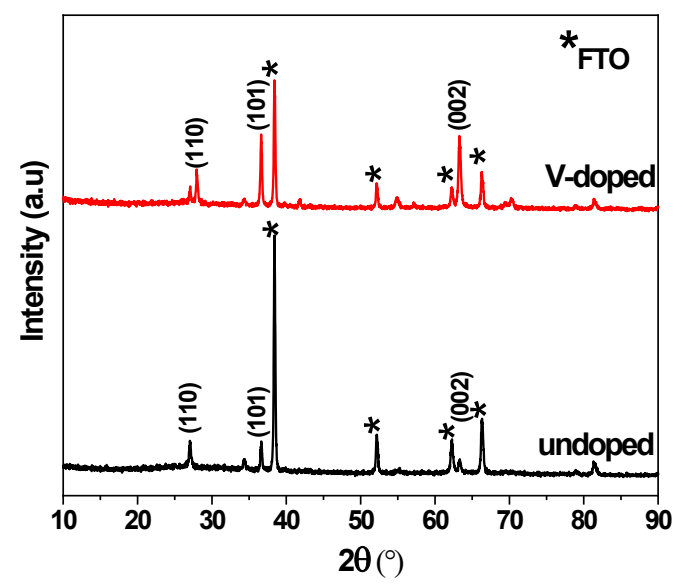

Fig. 4. XRD spectra of the undoped and V-doped TNA.

\section{B. Humidity Sensor}

In order to gauge the performance of the humidity sensor, each device was placed in a humidity chamber and the humidity level was elevated from $40 \%$ to $90 \%$ Relative Humidity (RH), before going back to $40 \%$ RH. The output signal value from the microcontroller was recorded at every $10 \%$ RH interval. Fig. 5 shows the humidity sensing response of the undoped and V-doped humidity sensor. Both samples depict sharp increase in signal intensity when the humidity was increased from $40 \%$ to $90 \% \mathrm{RH}$, before going back down when the humidity was reduced to $40 \%$ $\mathrm{RH}$, suggesting that both type of sensor are able to sense the changes in humidity. The sensitivity value, $S$ was calculated using the following equation

$S=\frac{R_{a}}{R_{r h}}=\frac{\text { Output signal at } 90 \% R H}{\text { Output signal at } 40 \% R H}$

From the calculation, the undoped TNA sample recorded $S$ value of 9.9 while the V-doped TNA at 15.0.

The improvement to the $S$ value for the V-doped TNA can be attributed to several factors. It is postulated that the 
main contributing factor is the increased size of the $\mathrm{V}$ doped TNA. The mechanism of humidity detection for a resistive type humidity sensor is the modulation of the film's resistance with the changes in relative humidity. When water molecules are absorbed on the thin film's surface, more charge carrier in the form of electron or ions are available in the thin films thus increasing the thin film's conductivity [23]. As can be seen from the FESEM images, the V-doped TNA are having larger nanorods diameter resulting in a more condense packed nanorods array. It is believed that the closely connected nanorods array will facilitate the movement of the charge carrier, resulting in higher sensitivity. Even though some other researchers have argued that smaller diameter nanorods have the advantage of higher surface area compared to the larger ones, it is believe that in our case, the effect of better electron transportation surpasses this effect.

Furthermore, as mentioned earlier in the XRD result section, the crystallinity of the V-doped TNA is better than the undoped TNA, which is evident by its higher peak intensity. Since better crystallinity is often associated with increased conductivity [24], it is conceivable that this improvement also plays a role in enhancing the sensitivity of the V-doped TNA sensor.

Another possible reason for the improvement seen in $\mathrm{V}$ doped TNA sensor sensitivity value is through the increase in defect sites particularly oxygen vacancies, usually associated with metal doping of $\mathrm{TiO}_{2}$. This defect sites would increase the amount of trapped electron which will then be liberated by the adsorption of water molecules [25].

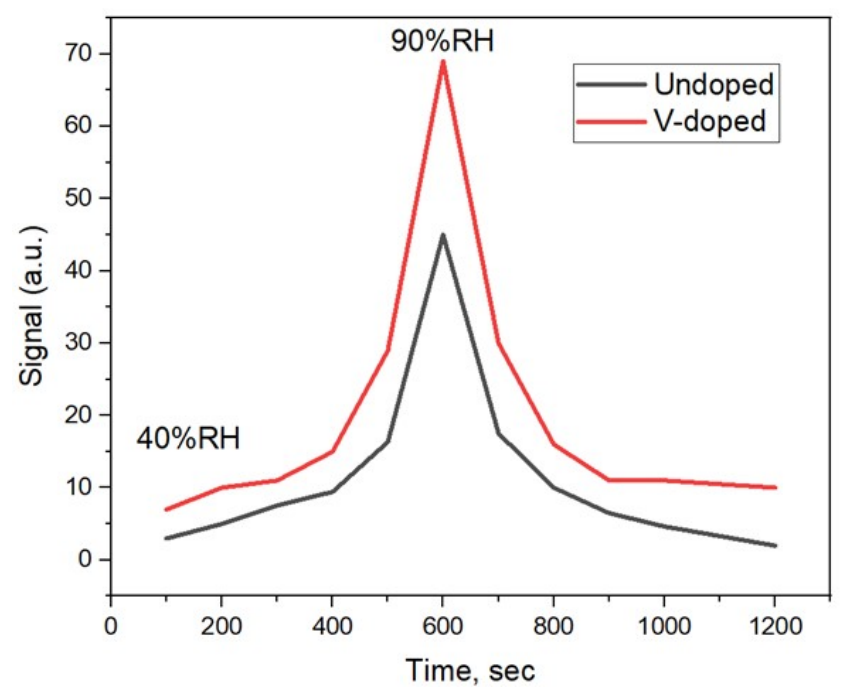

Fig. 5. Humidity sensing response of the undoped and V-doped humidity sensor.

\section{CONCLUSION}

V-doping of TNA was achieved through a facile solution immersion method and its structural properties were investigated before being tested for humidity sensor application. Compared to the undoped TNA, the V-doped device showed improvement in term of sensitivity. This improvement is attributed to the enlargement of nanorods diameter, enhancement in the crystallinity and the increase in oxygen vacancy defect sites of the V-doped sample. These findings could help improve the performance of $\mathrm{TiO}_{2}$-based resistive type humidity sensor.

\section{ACKNOWLEDGMENT}

The authors would like to thank Faculty of Electrical Engineering and Institute of Research Management and Innovation (IRMI), UiTM for their contribution to this work.

\section{REFERENCES}

[1] Lu, J., et al., Humidity sensor based on heterogeneous $\mathrm{CoTiO}_{3} / \mathrm{TiO}_{2}$ film with vertically aligned nanocrystalline structure. Vacuum, 2019. 163: p. 292-300.

[2] Chung, C.K., et al., Total effective surface area principle for enhancement of capacitive humidity sensor of thick-film nanoporous alumina. Materials Letters, 2020. 260: p. 126921.

[3] Kano, S. and M. Fujii, All-Painting Process To Produce Respiration Sensor Using Humidity-Sensitive Nanoparticle Film and Graphite Trace. ACS Sustainable Chemistry \& Engineering, 2018. 6(9): p. 12217-12223.

[4] Dai, J., et al., Ultrafast Response Polyelectrolyte Humidity Sensor for Respiration Monitoring. ACS Applied Materials \& Interfaces, 2019.

[5] Bindra, P. and A. Hazra, Impedance behavior of n-type $\mathrm{TiO}_{2}$ nanotubes porous layer in reducing vapor ambient. Vacuum, 2018. 152: p. 78-83.

[6] Wang, Q., et al., Resistive and capacitive response of nitrogendoped $\mathrm{TiO}_{2}$ nanotubes film humidity sensor. Nanotechnology, 2011. 22(2): p. 025501.

[7] Gong, M., et al., 2D $\mathrm{TiO}_{2}$ nanosheets for ultrasensitive humidity sensing application benefited by abundant surface oxygen vacancy defects. Sensors and Actuators B: Chemical, 2018. 262: p. 350-358.

[8] Musa, M.Z., et al., Fabrication and structural properties of flowerlike $\mathrm{TiO}_{2}$ nanorod array films grown on glass substrate without FTO layer. Materials Letters, 2020. 273: p. 127902.

[9] Liang, F., et al., $\mathrm{TiO}_{2}$ nanotube-based field effect transistors and their application as humidity sensors. Materials Research Bulletin, 2012. 47(1): p. 54-58.

[10] Farzaneh, A., M.D. Esrafili, and Ö. Mermer, Development of $\mathrm{TiO}_{2}$ nanofibers based semiconducting humidity sensor: adsorption kinetics and DFT computations. Materials Chemistry and Physics, 2020. 239: p. 121981.

[11] Wang, G., et al., Photoelectrochemical Study on Charge Transfer Properties of $\mathrm{TiO}_{2}-\mathrm{B}$ Nanowires with an Application as Humidity Sensors. The Journal of Physical Chemistry B, 2006. 110(43): p. 22029-22034.

[12] Jyothilal, H., et al., Humidity sensing and breath analyzing applications of $\mathrm{TiO}_{2}$ slanted nanorod arrays. Sensors and Actuators A: Physical, 2020. 301: p. 111758.

[13] Bai, J. and B. Zhou, Titanium Dioxide Nanomaterials for Sensor Applications. Chemical Reviews, 2014. 114(19): p. 10131-10176.

[14] Li, Z., et al., The effect of Co-doping on the humidity sensing properties of ordered mesoporous $\mathrm{TiO}_{2}$. Applied Surface Science, 2017. 412: p. 638-647.

[15] Farzaneh, A., et al., Experimental and theoretical study of $\mathrm{TiO}_{2}$ based nanostructured semiconducting humidity sensor. Ceramics International, 2019.

[16] Raji, P., H.S. Binitha, and K. Balachandra Kumar, Synthesis and Humidity Sensing Properties of Sn-Doped Nano. Journal of Nanotechnology, 2011. 2011: p. 6. 
[17] Li, G., et al., Ethanol sensing properties and reduced sensor resistance using porous $\mathrm{Nb}_{2} \mathrm{O}_{5}-\mathrm{TiO}_{2}$ n-n junction nanofibers. Sensors and Actuators B: Chemical, 2019. 283: p. 602-612.

[18] Li, T.Y., et al., Giant and controllable humidity sensitivity achieved in $\left(\mathrm{Na}+\mathrm{Nb}\right.$ ) co-doped rutile $\mathrm{TiO}_{2}$. Sensors and Actuators B: Chemical, 2019. 293: p. 151-158.

[19] Wang, T. and $\mathrm{T}$. $\mathrm{Xu}$, Effects of vanadium doping on microstructures and optical properties of $\mathrm{TiO}_{2}$. Ceramics International, 2017. 43(1, Part B): p. 1558-1564.

[20] Yusoff, M.M., et al., Coupling heterostructure of thicknesscontrolled nickel oxide nanosheets layer and titanium dioxide nanorod arrays via immersion route for self-powered solid-state ultraviolet photosensor applications. Measurement, 2020. 149: p. 106982.

[21] Faia, P.M. and J. Libardi, Response to humidity of $\mathrm{TiO}_{2}: \mathrm{WO}_{3}$ sensors doped with $\mathrm{V}_{2} \mathrm{O}_{5}$ : Influence of fabrication route. Sensors and Actuators B: Chemical, 2016. 236: p. 682-700.

[22] Liu, H., Y. Wu, and J. Zhang, A New Approach toward CarbonModified Vanadium-Doped Titanium Dioxide Photocatalysts. ACS Applied Materials \& Interfaces, 2011. 3(5): p. 1757-1764.

[23] Ismail, A.S., et al., Fabrication of hierarchical Sn-doped $\mathrm{ZnO}$ nanorod arrays through sonicated sol-gel immersion for room temperature, resistive-type humidity sensor applications. Ceramics International, 2016. 42(8): p. 9785-9795.

[24] Wochnik, A.S., et al., Increasing Crystallinity for Improved Electrical Conductivity of $\mathrm{TiO}_{2}$ Blocking Layers. ACS Applied Materials \& Interfaces, 2013. 5(12): p. 5696-5699.

[25] Blank, T.A., L.P. Eksperiandova, and K.N. Belikov, Recent trends of ceramic humidity sensors development: A review. Sensors and Actuators B: Chemical, 2016. 228: p. 416-442.

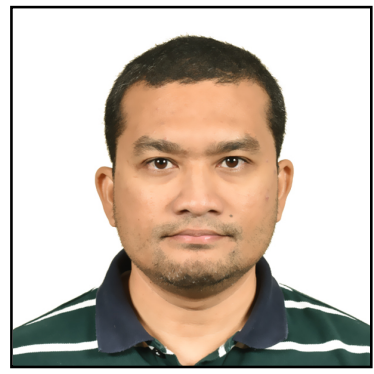

M.Z. Musa was born in Perak, Malaysia in 1981. He received his bachelor's degree in Electronics and Electrical Engineering from Ibaraki University, Japan in 2005 and master's degree from Universiti Teknologi MARA (UiTM), Malaysia in 2012. He works as Senior Lecturer at Universiti Teknologi MARA Cawangan Pulau Pinang. Currently, he is doing his PhD at NANO-Electronic Centre (NET), Faculty of Electrical Engineering, Universiti Teknologi MARA, Malaysia in the area of nanomaterial.

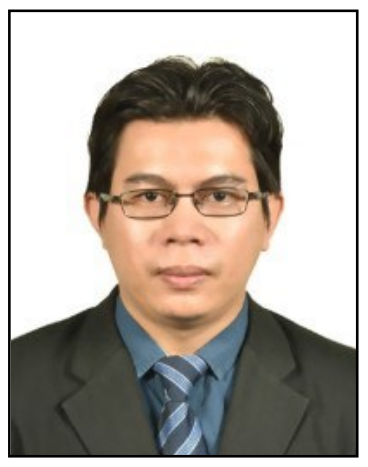

M.H. Mamat received his bachelor's degree in electrical \& electronic engineering and information engineering from Nagoya University, Japan and both of his PhD's and master's degrees in electrical engineering from Universiti Teknologi MARA (UiTM), Malaysia. He is currently an associate professor at the Faculty of Electrical Engineering, UiTM. His research interests range over metal oxide semiconductors and nanodevices.

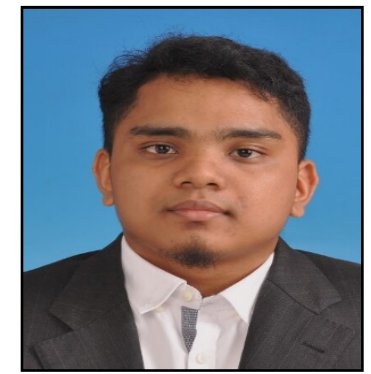

M.A. Othman received his Diploma and bachelor's degree in electrical engineering from Universiti Teknologi MARA. His research areas are nanomaterial fabrication and electronic circuit design.

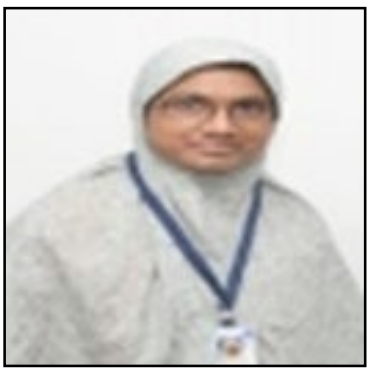

I.B Shameem Banu received her first $\mathrm{PhD}$ in physics from Madurai Kamaraj University. She received her second $\mathrm{PhD}$ in condensed material physics from Anna University, Chennai, India. She is currently a professor at the Department of Physics, B.S. Abdur Rahman Crescent Institute of Science and Technology, Chennai, India.

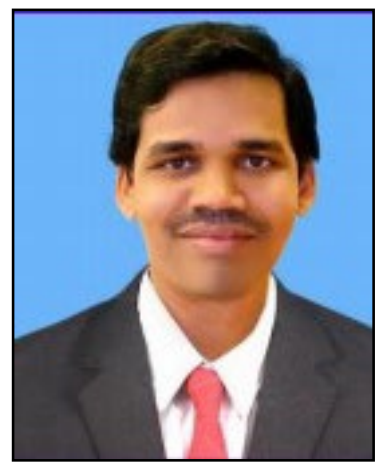

N. Vasimalai received his B.Sc and M.Sc in chemistry from Madurai Kamaraj University, Tamil Nadu, India. He received both M.Phil and $\mathrm{PhD}$ in Chemistry from Gandhigram Rural University, Tamil Nadu, India. He worked as Postdoctoral Fellow at National Cheng Kung University, Taiwan and Marie Curie Postdoctoral Fellow (Co-Fund) at International Iberian Nanotechnology Laboratory, Portugal. He is currently working as Assistant Pofessor at the Department of Chemistry, B.S. Abdur Rahman Crescent Institute of Science and Technology, Chennai, India. His field of specialization has been focused on the synthesis of fluorescent nanomaterials and their biosensor and biomedical applications.

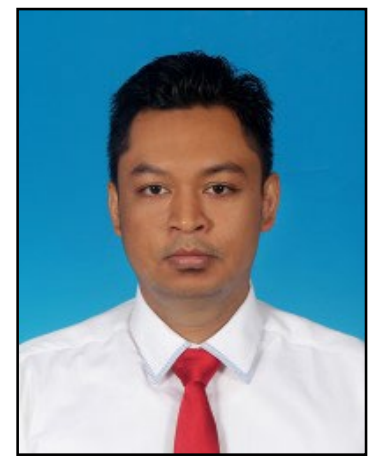

M.F. Malek received his bachelor's degree in physics from Universiti Teknologi MARA (UiTM), Malaysia. He is also a research member of NANO-SciTech Centre (NST), Institute of Science (IOS), UiTM. He received both master's degree and $\mathrm{PhD}$ in electrical engineering from UiTM. He is currently a senior lecturer at the Faculty of Applied Sciences, UiTM. His focused research area is on nanotechnology, nanomaterials, and nanodevices. 


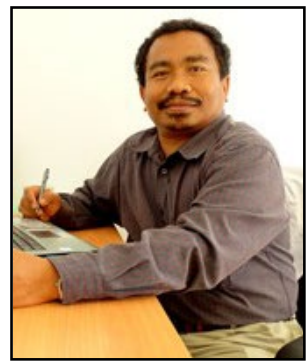

M. Rusop received his bachelor's degree in engineering from Nagoya University, Japan. He received his Master and $\mathrm{PhD}$ in engineering from Nagoya Institute of Technology, Japan. He is currently a professor at the Faculty of Electrical Engineering, Universiti Teknologi MARA (UiTM), Malaysia. 